\title{
Den intellektuelle og politiske Georg Brandes
}

\author{
Svendsen, Erik
}

Published in:

Tijdschrift voor Skandinavistiek

\section{Publication date:}

2018

\section{Document Version}

Også kaldet Forlagets PDF

Citation for published version (APA):

Svendsen, E. (2018). Den intellektuelle og politiske Georg Brandes. Tijdschrift voor Skandinavistiek, 36(2), 261268.

\section{General rights}

Copyright and moral rights for the publications made accessible in the public portal are retained by the authors and/or other copyright owners and it is a condition of accessing publications that users recognise and abide by the legal requirements associated with these rights.

- Users may download and print one copy of any publication from the public portal for the purpose of private study or research.

- You may not further distribute the material or use it for any profit-making activity or commercial gain.

- You may freely distribute the URL identifying the publication in the public portal.

Take down policy

If you believe that this document breaches copyright please contact rucforsk@kb.dk providing details, and we will remove access to the work immediately and investigate your claim. 


\title{
DEN INTELLEKTUELLE OG POLITISKE GEORG BRANDES
}

\author{
Erik Svendsen \\ Roskilde Universitet \\ evs@ruc.dk
}

\begin{abstract}
Georg Brandes is mostly known as a literary critic, while there has been much less focus on his comprehensive political writing. Thus, more work needs to be done here, not least because Brandes presents himself in these texts as an intellectual who thinks internationally and unites an ability to defend enlightenment values with a critique of modernity. The analytical focus of the contribution is Brandes' two late monographs Verdenskrigen (1916) (The Great War) and Tragediens anden Del. Fredsslutningen (1919) (Part Two of the Tragedy. The Peace Treaty). In these two books, Brandes reports and reflects on militarism, imperialism, nationalism, free trade and communication across borders. While the young Brandes optimistically regarded the Enlightenment as having advanced humanity, he became much more sceptical in his later years. The First World War and its aftermath proved to him that there was a general lack of interest in rationality, internationalism and freedom. On the one hand, Brandes argued in favour of modernity but, on the other, he was also a sharp critic of modernity's double standards and hypocrisy, which he found on both the winning and the losing sides. Objectively, Brandes observed that the war changed society after 1918. Western societies were deeply internally divided, which manifested not least in the class struggle. Brandes cannot be accused of sympathizing with either Lenin or the Danish labour movement; however, he happily accepted invitations to give educational speeches to the workers. As a citizen, and a liberal regarding financial policy, Brandes was frightened at the thought of Communism spreading to Europe, but defended Russia against international sanctions, which he thought was the incorrect way to respond to Lenin. The contribution considers that Georg Brandes' writings are not devoid of self-contradiction. However, it is argued that he actually manages to speak with two voices without betraying his fundamental belief in the ideal of enlightenment. In his time, he was criticized for his persistent defence of neutrality. However, what is exemplary in Brandes' work as an intellectual is that he managed to criticize all parties who, in different ways, betrayed the ideal of progress. Thus, le citoyen and the free intellectual defeat le bourgeois in Brandes.
\end{abstract}

\section{Nøgleord}

Georg Brandes, den intellektuelle, modernitet \& modernitetskritik, første verdenskrig, demokrati, aristokrati

I 1919 udgiver den 67årige Georg Brandes artikelsamlingen Tragediens Anden Del. Fredsslutningen. Den fredsslutning, der hentydes til, er selvsagt den, som skulle afslutte den første verdenskrig, men som reelt kom til at blive en af årsagerne til den anden verdenskrig. Brandes forudser den mulighed, og indigneret påtaler han det fatale i de allieredes politiske vendetta, som gjorde det mere end vanskeligt for Tyskland at komme på fode efter nederlaget

Tijdschrift voor Skandinavistiek 36(2), 2018/19 (co) Eү

\footnotetext{
Except where otherwise indicated, the content of this article is licensed and distributed under the terms of the Creative Commons Attribution 3.0 License, which permits unrestricted use, distribution, and reproduction in any medium, provided the original work is properly cited.
} 
i 1918. Det er typisk for Brandes som intellektuel at solidarisere sig med tabere og fors $\varnothing \mathrm{ge}$ at råbe offentligheden op, påtale uretfærdigheden (Eyerman 1994, Said 1994). Det gør han såvel i en dansk som international offentlighed, idet bogen bliver oversat til flere sprog, ligesom forgængeren, Verdenskrigen (1916) blev det (Knudsen, 2004).

Brandes' forfatterskab er mangfoldigt og ordrigt. Han er mest kendt som litteraturkritiker, men jeg vil i denne sammenhæng betone værker og artikler som omhandler politiske forhold. Der er karakteristisk for Brandes, at han gør opmærksom på undertrykkelse af mindretalsgrupper. Det kunne være sønderjyder i Tyskland, armenere, jøder eller polakker. Igennem hele forfatterskabet finder man en trang til at angribe magtmisbrug, ideologisk såvel som materielt, og denne retfærdighedssans kom mange befolkningsgrupper til gode. Brandes var internationalist, og i de sene dybt anfægtede værker dristede han sig til at tænke globalt i sin kritik af de vestlige landes politik over for andre verdensdele. Der er sider i Tragediens Anden Del, som virker næsten profetiske i vurderingen af, hvordan den vestlige verden vil tabe handelskrig mod Kina og Asien, ligesom bogen peger frem mod behovet for overstatslig internationalt og retfærdigt samarbejde, hvis verden skal undgå at bryde sammen i kaos.

\section{Det tabte fremskridt}

Georg Brandes skriver ikke essays (det gør han faktisk sjældent), derimod ræsonnerende artikler mærket af en bemærkelsesværdig journalistisk research (målt i forhold til sin samtid, ikke mindst den danske), og man er sjældent i tvivl om Brandes' ærinde. Brandes vil via informationer og argumenter vække sin læser, kalde på refleksion, og i forhold til de to bøger om den første verdenskrig for så vidt også handling i form af modstand mod den politik, som de allierede praktiserede overfor Tyskland. Hvor essayisten er undersøgende, er den politisk orienterede Brandes indigneret, partisk, fortvivlet - på oplysningsideologiens vegne. Essayisten er gerne legende; Brandes er manende alvorlig, for hans agenda kalder ikke på latter men politiske beslutninger, der skal ændre den herskende (stor)politik. Når han skriver Verdenskrigen og Tragediens Anden Del, er han en oplysningstænker, der konstaterer, at oplysningen har tabt teten. I stedet for fornuft, retfærdighed, tolerance, sandhed, universalisme og internationalisme ser han en verden i brand. Europa er i krig, og den breder sig ud til andre verdensdele. Nationalisme, militarisme, irrationel had rettet mod fremmede, mod fjenden sejrer, og de intellektuelle, mange af Brandes' gamle kolleger, har svigtet ved at skrive begejstret om krigen. Fremskridtets tog er løbet af sporet; død og ødelæggelse har erstattet drømmen om en udvikling båret af oplysning, rationalitet, frihandel og internationalt samkvem. Militarisme har skubbet pacifismen væk. De gamle autoriteter genopstår, og religiøse almagtsforestillinger i nationalt regi sætter sekulariseringen under pres (Benda, 1928).

Verdenskrigen og Tragediens Anden Del er skrevet af en mand i dyb krise, fordi den modernitet, som Brandes har advokeret for, er blevet et misfoster. De to bøger handler ikke kun om en fritænker i krise, de handler om en kultur som nærmer sig en afgrund. Georg Brandes starter sit forfatterskab med at ruske op i den danske biedermeier-kultur, han ender med at kritisere den vestlige verdens kapitalisme, der forråder sit eget grundlag.

Et langt stykke af vejen troede han, at fremskridtet ville sejre, som her i en engagerende artikel fra 1900 om undertrykkelse af armenere:

Tijdschrift voor Skandinavistiek 36(2), 2018/19

Except where otherwise indicated, the content of this article is licensed and distributed under the terms of the Creative Commons Attribution 3.0 License, which permits unrestricted use, distribution, and reproduction in any medium, provided the original work is properly cited. 
Men da alt umuligt kan være Kaos, eftersom de videnskabelige, intellektuelle og industrielle Fremskridt uafladeligt ophobes, udbredes og formerer sig ved Berøring med hverandre, da der, trods Alt, trods Folkeundertrykkelse og Klasseundertrykkelse og religiøs Forfølgelse og Sejgpining af enhver selvstændig eller fremragende Enkelt, ja, trods Massemord af Hundredetusinder i et ulykkeligt Folk, nødvendigvis, uundgaaeligt finder et Slags Fremskridt Sted, saa bliver Nedslaget i Ens Sind til allersidst dog netop Indtrykket af den forfærdelige Tidsspilde (Brandes 1900/1987, 128).

Til sammenligning har pessimismen vundet over fremskridtstroen i Tragediens Anden Del:

Og Sandheden er den, at hvad vi i de sidste fire Aar har været Vidner til, har været en Explosion af dulgte Kræfter i Menneskeheden, hvis Styrke og Omfang ingen Fremskridtstroende havde formodet, en Explosion uden Mage af Brutalitet, Løgn, gensidig Misundelse og indbyrdes Bagvaskelse, umaadeligt Hykleri, der under sit Udbrud har overskyllet alle civiliserede Folkeslag og adskillige halvciviliserede eller uciviliserede (Brandes 1919, 20).

Bemærk at Brandes som de fleste andre i sin tid opererer med en hierarkisk civilisationsakse, hvor den vestlige rager højt op over alle andre "uciviliserede", hvilket ikke forhindrer at Brandes i samme bog anholder de vestlige staters imperialisme og kolonipolitik, der rammer netop befolkninger, som ikke matcher den herskende civilisation.

Det store forfatterskab rummer mange artikler, der er opråb til offentligheden om uretfærdigheder. Brandes bruger bevidst sin intellektuelle kapital som genvej til indflydelse (for eksempel Brandes 1901, 1903, 1905/1987). Han har i 1919 kun hån til overs for det Folkeforbund, som ikke evner at finde frem til en rimelig og fremtidssikret fred - men han påkalder sig omvendt et forbund af internationale intellektuelle, som måske kan gavne sagen (Brandes 1919, 7). Den intervention er i pagt med de fordringer for den intellektuelle der manifesterede sig i Dreyfus-affæren som er den historiske baggrund for den intellektuelle bliver etableret som term og figur (Thing, 1993).

\section{Den frie intellektuelle og formidleren}

Brandes er en sammensat figur; han er både idealist og materialist, nationalist og internationalist, journalist, reporter, kronikør og kritiker, partisk og distanceret. Men han er først og sidst en genuin fri intellektuel, der lever af at skrive til et internationalt publikum. At Brandes aldrig rigtig blev anerkendt af universitetet i Danmark var således paradoksalt nok med til at udvide hans horisont og gøre ham endnu mere opmærksom på det internationale. Det mere eller mindre nødtvungne ophold i Berlin fra 1877 til 1883 accentuerede kun sansen for at inddrage en bred kulturel og politisk kontekst.

På den måde er der en lige linje fra den metode, som han annoncerer i introduktionen til Hovedstrømninger og som får ham til at blive en formidler af både ældre og moderne litteratur og frem til den ældre Brandes, som kritiserer stormagter for at undertrykke mindretalsgrupper og fører en krig, der kuldkaster fremskridtet. Politik og litteratur hænger sammen. Brandes

Tijdschrift voor Skandinavistiek 36(2), 2018/19 ((c) EY

Except where otherwise indicated, the content of this article is licensed and distributed under the terms of the Creative Commons Attribution 3.0 License, which permits unrestricted use, distribution, and reproduction in any medium, provided the original work is properly cited. 
formidler nordisk litteratur til internationale læsere, tyske og franske læsere for eksempel, og samtidig formidler hans russisk, fransk, tysk og engelsk litteratur til det skandinaviske publikum. På samme måde kan Brandes karakteriseres som national kosmopolit (Berthelsen m.fl., 2004), og hans ambivalens overfor at promovere det moderne samfund og samtidig hylde de store personligheder, som de egentlige bærere af kulturen, vidner om en spænding, en modsigelser der ligger i moderniteten: Brandes var ikke udpræget begejstret for demokratiet, men det var ikke desto mindre udbredelse af rettigheder til de mange, han kom til at virke for.

Han tog de svages parti, selv om han som Nietzsche helst så at geniet kom til sin ret. De store ånder skulle guide befolkningen, for de få havde set lyset, mens flertallet ragede rundt $\mathrm{i}$ et åndeligt mørke: "Fra de Enkelte, ikke fra Folkevælden, udgaar alle afgørende fremskridt" (citeret efter Lykkeberg, 2012, 234). Folk skulle dannes til demokratiet, og dermed havde de intellektuelle en fornem (og vanskelig) opgave. Brandes kunne skrive rosende om arbejderbevægelsen (Lasalle for eksempel), hvorfor han kom til at spille en ikke uvæsentlig rolle som foredragsholder for oplysningshungrende arbejdere, selv om han på den anden side sandelig også havde distance til arbejderkulturen, ikke mindst kommunismen som han var mindst lige så bange for som borgerskabet var det. På én og samme gang var Brandes en folkeoplyser og en åndsaristokrat som mente, at langt størsteparten af befolkningen havde brug for gedigen kulturel opdragelse, hvis demokratiet skulle give bare lidt mening.

\section{Citoyen fremfor bourgeois}

Sven Møller Kristensen (1980) gør i sin bog om Brandes opmærksom på en afgørende distinktion mellem bourgeois og citoyen, som præciserer spændinger hos Brandes. Han er varm fortaler for frihandel og på den måde forener han økonomisk liberalisme med ønsket om international fred, fordi frihandel i hans $\varnothing j n e$ forbinder folk på tværs af nationer fremfor at splitte. Brandes begejstring for den frie tanke og videnskabelige fremskridt går også hånd i hånd med borgerskabets fremmarch, men som Møller Kristensen viser, er Brandes overvejende citoyen i sin måde at advokere for det moderne samfund på. Som intellektuel er det de almene interesser Brandes vil nyde fremme, og på den konto bliver han også en kritiker af tendenser i den borgerlige kultur, ikke mindst selvfølgelig den autoritære konservatisme og religionen. Når de nationalliberale og borgerskabet ikke kan leve op til de borgerlige fordringer om fremskridt, "tillid til fremtiden, vovelyst og mod" som Brandes bemærker i en afgørende tekst, "Om Nationalfølelse" (1894), siger han fra.

Som en anden spirende materialhistoriker bemærker han, at omstillingen til smøravl viser, at andelsbevægelsen formår at omstille sig til de nye tider, mens det ligger tungere med det borgerlige Danmarks anerkendelse af opbruddet i åndslivet. Ja mere end det: Som et ekko af Nietzsche noterer Brandes, at det er trællesindet, der belønnes, mens talenter udviskes og retsfølelsen decimeres. Friheden taber til konformitet. Løsenet er en idealistisk fordring om en genetablering af modet som drivkraft, men det er også, og på dette punkt sætter Brandes' dialektiske sans sig igennem, en betoning af spændingen mellem på den ene side behovet for verdensborgerfølelse og på den anden side nationalfølelsen: "Verdensborgerfølelsen er ikke blot meget vel mulig paa Grundlag af Nationalfølelsen, men den er unaturlig uden den" (Brandes, 1894, 199). Hans indædte modstandere mente, at det var jøden i Brandes, som gjorde

Tijdschrift voor Skandinavistiek 36(2), 2018/19

Except where otherwise indicated, the content of this article is licensed and distributed under the terms of the Creative Commons Attribution 3.0 License, which permits unrestricted use, distribution, and reproduction in any medium, provided the original work is properly cited. 
ham udansk; jeg mener, at det er verdensborgeren i Brandes, som kvalificerer ham som kritiker - af såvel danske som udenlandske forhold, herunder litteratur.

Det er den samme dialektiske tænkning mellem verdensborger og nationalist, det fjerne og det nære, der præger litteraturtilgangen i Hovedstrømninger. Jeg citerer fra den indledningen, hvor der argumenteres for den komparative metode:

Den sammenlignende Litteraturbetragtning har den dobbelte Charakter at nærme det Fremmede til os saaledes, at vi kunne tilegne os det, og fjerne vort Eget fra os saaledes, at vi kunne overskue det. Man seer hverken hvad der ligger Øiet altfor nær eller altfor fjernt" (Brandes 1872/1968, 87).

Det kan forekomme banalt men det faktum, at Brandes mestrede flere sprog, havde en international horisont og var interesseret $i$ at se det danske med fremmede briller samt at han kommunikerede med et stort internationalt publikum, gjorde ham til en indlysende intellektuel.

Tragediens Anden del er en situationsrapport og en genreblanding. Brandes gengiver en række oplysninger, noget tenderer en citatmosaik, mens det refleksive dominerer i andre kapitler afløst af det polemiske i endnu andre kapitler. Det er også vidt forskellige forklaringer på verdenssituationen Brandes lancerer. Det kan for det første være manglen på store politiske personligheder, som kunne have reddet staterne ud af redeligheden, eller det kan for det andet være oplevelsen af at tiden ligner et hobbesiansk anarki, hvor alle stater stræber efter at opnå egen sikkerhed på bekostning af hensyn til internationalt samarbejde. For det tredje kan det være de forringede muligheder for frihandel, eller det kan for det fjerde helt overordnet være en pointering af at globaliseringen af kapitalismen må ende med at udløse en verdenskrig. Brandes er tilhænger af moderniteten - og bedriver modernitetskritik.

Man kan kritisere forfatteren for at svinge mellem forskellige udlægninger, omvendt kan man rose ham for at have blik for krigens kompleksitet. Brandes erfarer, at sandheden fordufter i krigstid, og det betyder kun, at de lokale medier bliver endnu mere løgnagtige og manipulerende: Brandes har ikke meget respekt for den mediekultur, han underst $\varnothing t t e d e ~ a k t i v t$. Det kan man kalde et paradoks. Paradokstænkning udfolder Brandes virtuost i et kapitel, hvor han gennemgår fredsaftalens daværende punkter, og det hver gang ved at modstille ide med realitet: ét er hvad aftalen siger, noget helt andet hvordan de sejrende parter de facto gebærder sig, eller noget andet er hvordan den faktiske politiske situation er. Jeg kan illustrere ved at tage punkt 14:

Et almindeligt Folkeforbund skal dannes for at sikre store og smaa Stater i samme Grad politisk Uafhængighed og Landenes Udelighed. (Foreløbigt er Tyskland og Rusland udelukkede fra Folkenes Forbund, der endnu kun har delt Verden i to fjendtlige Lejre) (Brandes, 1919, 146).

\section{Sejrherrernes hykleri}

Hykleri eller dobbeltmoral er en ledetråd i fremstillingen. Flere gange gør Brandes opmærksom på at også undertrykte har en tendens til selv at reproducere undertrykkelse, eller som en variant

Tijdschrift voor Skandinavistiek 36(2), 2018/19 (cc) Er

\footnotetext{
Except where otherwise indicated, the content of this article is licensed and distributed under the terms of the Creative Commons Attribution 3.0 License, which permits unrestricted use, distribution, and reproduction in any medium, provided the original work is properly cited.
} 
heraf: en udtalt trang til at kritisere andre staters undertrykkelse, mens man tier om den undertrykkelse man selv bedriver:

På den anden Side Hykleriet, et Hykleri i største Stil, der uafbrudt forkyndte sin Kamp for Folkefrihed og Folkeret, skøndt de Allierede, baade saalænge de kæmpede i Fællig med Czardømmet og senerehen, selv undertrykte et mangfoldigere Gange større Milliontal af Mennesker end de tyranniske Centralmagter, Tyskland, Østrig-Ungarn, Bulgarien, Tyrkiet" (Brandes, 1919, 37-38).

En sådan kritik er nødvendig og vidner om intellektuel integritet. Brandes' modstandere så den som forræderi - og dermed viser hans modstandere, hvor fatalt systemapologetiske intellektuelle også kan være.

Nøgternt ser Brandes, at krigen som fænomen skifter scene uden at den skifter væsen, og det selv om der kommer fredstid. Kampen mellem staterne afløses efter 1918 af en social krig, af klassekamp, eller krigen manifesterer sig i en særlig variant i den internationale boykot af det kommunistiske Rusland. Brandes er alt andet end begejstret for Lenins revolution, alligevel kritiserer Brandes den sanktionspolitik, der føres over for landet. Borgeren og den økonomiske liberalist Brandes er skræmt ved tanken om, at kommunismens ideer skal sprede sig til Europa, mens citoyen i Brandes får ham til at forsvare et system, han er inderligt imod, fordi han kan se hvilke konsekvenser boykotten vil kunne få. Der går en lige linje fra Pariskommunen i 1871 (beskrevet med ord som "Pøbelforbitrelse" og "Underklassehadet", 31) og frem til den russiske revolution i 1917 (beskrevet som "Svulst" og "Rædselsstyre", 50) - sporene skræmmer. Men Brandes ryster ikke på hånden i sin kritik af den borgerlige, kapitalistiske verden, som prøver at modgå kommunismen, men det med en politik, der snarere gør ideologien mere attraktiv for de trængte masser.

Man kan mene, at Brandes er selvmodsigende. Jeg vil hertil sige, at han formår at tale med to tunger uden at forråde sit oplysningsideal. Han kritiseres for sin insisteren på at være neutral, ikke at kritisere Tyskland, men det forbilledlige ved Brandes' intellektuelle ageren er, at han formår at kritisere alle parter, der forråder fremskridtssamfundenes idealer. Cityoen og den frie intellektuelle vinder over den traditionelle intellektuelle og bourgeoisen i Brandes.

\section{En aristokratisk demokrat?}

Georg Brandes havde et udtalt skeptisk forhold til demokratiet. Det fremgår utvetydigt af programteksten "Det Store Menneske, Kulturens Kilde", der oprindelig blev skrevet i 1890 og revideret i 1901. Distinktionen mellem stjernerne og vandbærerne er afgørende. I en konfliktfyldt tid, hvor konservative kræfter forsøger at holde på den politiske (og materielle) magt, plæderer oplysningens repræsentant for en elitær orden, der til forveksling ligner den herskende. Det store flertal, vandbærerne, skal anerkende hierarkiet, og samtidig skal den åndelige overklasse insistere på at promovere den kulturelle essens:

Det gælder ganske vist om at optugte Masserne til at forstaa, at de har Pligter mod de ualmindelige Mennesker, at de bør holde deres Dom tilbage, hvor de ikke kan overskue eller forstaa, men denne Fremgangsmaade er saare langsom. Det gælder derfor først

Tijdschrift voor Skandinavistiek 36(2), 2018/19 (co) EY

Except where otherwise indicated, the content of this article is licensed and distributed under the terms of the Creative Commons Attribution 3.0 License, which permits unrestricted use, distribution, and reproduction in any medium, provided the original work is properly cited. 
og fremmest om at gøre de saakaldte højest Dannede, de magthavende Personligheder det begribeligt, at de ikke er til for at spærre eller plumre Kulturkilderne men for at vogte dem (305).

Brandes fremstår som en urokkelig og elitær autoritet, men han plæderer på den anden side for egalitære principper, der er kerneværdier i demokratiet. Han hylder realismen, en kunst der gør opmærksom på undertrykkelse og samfundets skyggesider, alligevel er det en idealistisk forestilling, der er hans kendemærke. Brandes ville "en højere Aandskultur i Danmark", som han selv sagde i en tale fra 1883 (citeret efter Lykkeberg, 234). Den genuine demokratiske følelse kunne ligge på et lille sted: "i mit inderste hjerte hælder jeg mod den oplyste absolutisme" erklærer han i en anden tale (Lykkeberg, 236).

Brandes var klar i spyttet, men hvis han er fremskridtets mand, er han det unægtelig på en tvetydig måde. Det gør ham ikke til en dårlig intellektuel. Måske snarere en typisk: Intellektuelle har det bedst med at være konstitutionelt uafklarede (Said 1994, Goldfarb 1998, Hertel 2004 b, Misztal 2007, Svendsen 2016).

\section{Bibliografi}

Benda, J. (1927/2009). The Treason of the Intellectuals. London: Transaction Publishers.

Bertelsen, S. (m. fl. 2004). Europa i Danmark, Danmark i Europa. I Hertel 2004a.

Brandes, G. (1872/ 1968). Indledning til Hovedstrømninger i det 19de Aarhundredes Litteratur. I Essays. København: Gyldendal.

Brandes, G. (1889/1901). Friedrich Nietzsche. En Afhandling om aristokratisk Radikalisme. I Samlede Skrifter. Syvende Bind. København: Gyldendal.

Brandes, G. (1894/1902). Om Nationalfølelse. I Samlede Skrifter, tolvte bind. København: Gyldendal.

Brandes, G. (1901/1968). Det store Menneske, Kulturens Kilde. I Brandes. Essays. København: Gyldendal

Brandes, G. (1987). Armenien (1900), Nutidscivilisation (1901), Mano negra (1903), Den svageres Ret og Pligt (1905), Hunnertalen (1900). I Udvalgte skrifter bind 8: Journalistik og debat. København: Tiderne skifter.

Brandes, G. (1987). Politiske Grundspørgsmaal (1901) og Sagens Genoptagelse (1903). I Udvalgte skrifter 8: Journalistik og debat. København: Tiderne skifter.

Brandes, G. (1916). Verdenskrigen. København: Gyldendal.

Brandes, G. (1919). Tragediens anden Del. Fredsslutningen. København: Gyldendal.

Clausen, J. S. (1994). Georg Brandes og Dreyfusaffaren. København: C.A. Reitzel.

Eyerman, R. (1994). Between Culture and Politics: Intellectuals in Modern Society. Cambridge: Polity Press.

Goldfarb, J.C. (1998). Civility and Subversion. The Intellectual in Democratic Society. Cambridge: Cambridge University Press.

Hertel, H. (2004a). Nødigt, men dog gerne. Det nye samfund, det nye livssyn, det nye kulturliv 1870-1900. I Hans Hertel (red. 2004) Det stadig moderne gennembrud. København: Gyldendal. 
Hertel, H. (2004b). Georg Brandes' kulturrevolution - og kulturkampen omkring Georg Brandes 1871-2004. I Hertel 2004.

Hertel, H. (2004c). Den storpolitiske Georg Brandes: nationalisme, kommunisme og fascisme 1900-1927. I Harsløf, O. (red. m.fl.) (2004): Georg Brandes og Europa: Forelaesninger fra 1. Internationale Georg Brandes Konference.København: Museum Tusculanum.

Lykkeberg, R. (2012). Alle har ret. Demokrati som princip og problem. København: Gyldendal. Misztal, B.A. (2007). Intellectuals and the Public Good. Creativity and Civil Courage. Cambridge: Cambridge University Press.

Said, E. (1994). Representations of the Intellectual. London: Vintage.

Svendsen, E. (2016). De integrerede intellektuelle. I Kultur og Klasse nr. 122. København: Medusa.

Thing, M. (1993). Kommunismens kultur. DKP og de intellektuelle 1918-1960. I-II. København: Tiderne skifter.

\section{Om forfatteren}

Erik Svendsen, lektor i litteratur og medier, RUC, Institut for Kommunikation og Humanistisk Videnskab. Litteraturanmelder på Jyllands-Posten. Blandt andet bidrag til Danske Digtere $i$ det 20. Arhundrede, I-III (2000-2), Dansk Litteraturs Historie 1960-2000 (2007) og fx udgivet Kieslowskis kunst (1996), Det Nye. Sonderinger i dansk littercer modernisme (1998), Littercere livliner. Kanon, klassiker, litteraturbrug (2011), Radioverdener. Auditiv kultur, historie og arkiver (2015), Kampe om virkeligheden. Tendenser i dansk prosa 1990-2010 (2015) samt Medieanalyse (2015) og Medieteori (2018). Min artikel om "Den intellektuelle Brandes" er et uddrag fra et kapitel om samme, der vil kunne læses i min bog De intellektuelle, som er berammet til udgivelse medio 2019. Dette bogprojekt er støttet af FKK og RUC.

Tijdschrift voor Skandinavistiek 36(2), 2018/19 (cc) Er 